\title{
Numerical simulation of transient heat transfer in friction-stir welding
}

\author{
Mehmet T. Pamuk ${ }^{1 *}$, Atilla Savaş ${ }^{1}$, Ömer Seçgin ${ }^{2}$, Emrah Arda ${ }^{3}$ \\ ${ }^{1}$ Piri Reis University Engineering Faculty, Tuzla 34940, Istanbul, Turkey \\ ${ }^{2}$ Piri Reis University Vocational School, Tuzla 34940, Istanbul, Turkey \\ ${ }^{3}$ Sakarya University, Serdivan 54050, Sakarya, Turkey
}

Corresponding Author Email: turgaypamuk@hotmail.com

https://doi.org/10.18280/ijht.360104

Received: 12 December 2017

Accepted: 20 March 2018

\section{Keywords:}

friction stir welding, aluminum, moving

heat source, transient heat conduction

\begin{abstract}
In this numerical study, three dimensional transient heat transfer analysis of Friction Stir Welding of two 8mm-thick AA-6061-T651 (an aluminum alloy) slabs has been performed. The numerical tool is the commercial package $\mathrm{Comsol}^{\odot}$ where the domain is modeled as a rectangular aluminum slab with a moving heat source along the centerline, as was the case in the experimental setup whose results have been compared to those of Comsol. Comparison has shown that moving heat source boundary condition to account for the heat input from the tool shoulder generates realistic results and thus can be a standard in similar problems. The findings of this work are believed to be a reference for future research on this area.
\end{abstract}

\section{INTRODUCTION}

FSW process was developed and patented by The Welding Institute in 1991 [1]. 'A rotating pin, attached to a shoulder piece, is translated along the joint line, causing localized plastic deformation, whilst frictional heating occurs due to contact between the tool and the material. In this process, welding zone is completely isolated from atmosphere which minimizes the formation of voids and large distortion in the weld zone. This new welding technique is extensively applied to aerospace, automobile and shipbuilding industries [2]'.

Chao et al. formulated the heat transfer of the FSW process into two boundary value problems a steady state BVP for the tool and a transient BVP for the work piece. They concluded that 95 per cent of the heat generated by the friction went into the work piece and the rest went into the tool [3].

Song and Kovacevic prepared a three dimensional transient model of the FSW process. Their work was both theoretical and experimental. They found that the calculated results were in good agreement with the experiments [4].

Song and Kovacevic introduced moving coordinate system to reduce the difficulty of modeling the heat generation due to the movement of the tool pin. The heat transfer process of the tool and work piece are coupled at the work piece/tool interface. The calculated result were in good agreement with the experimental ones [5].

Song and Kovacevic utilized again the moving coordinate system to reduce the difficulty of modeling heat generation between the work piece and the welding tool. The calculated results successfully demonstrated the heat-transfer process of the work piece in friction stir welding [6].

Schmidt and Hattel used a thermal pseudo-mechanical model in which the temperature-dependent yield stress of the weld material controls the heat generation [7].

Schmidt and Hattel made a heat transfer analysis of the FSW by taking into account the contact condition between the work piece and the tool. They mentioned the sticking and the sliding contact conditions [8]. Experimental characterization of the Heat Affected Zone properties of high carbon steel joined by rotary friction welding method was investigated by Mourad et al. [9]

In our present work, we used both steady state and transient analysis of the heat transfer which is generated by the friction and is transmitted to the work piece. We also made comparisons between the calculated results and experimental ones.

\section{THEORY}

Microscopic theories such as the kinetic theory of gases and the free-electron theory of metals have been developed to the point where they can be used to predict conduction through media. Continua may be classified according to variations in thermal conductivity. A continuum is said to be homogeneous if its conductivity does not vary from point to point within the continuum, and heterogeneous if there is such variation. Furthermore, continua in which the conductivity is the same in all directions are said to be isotropic, whereas those in which there exists directional variation of conductivity are said to be anisotropic. When Fourier's law is introduced into the law of conservation of thermal energy, the differential form of the equation of heat conduction may be obtained in terms of the temperature alone. If an isotropic continuum is considered, following equation is obtained:

$\rho C_{p} \frac{\partial T}{\partial t}=\nabla \cdot(k \nabla T)$

where the first term and second terms represent the transient part of the energy equation and the conduction, respectively [10]. This general equation can be rearranged with constant $\mathrm{k}$ (homogenous media) where the heat source moves: 
$\frac{\partial T}{\partial t}=\mathrm{V} \cdot \nabla T+\alpha \nabla^{2} T$

where $\mathbf{V}$ is the velocity vector and is the thermal diffusion coefficient. However, for very slow motions such as in the current situation, $\mathbf{V}=\mathbf{0}$ in Eq. (2) which then becomes same as Eq. (1). In this case, heat applied is considered to be of temporal and spatial variation, i.e., $\mathrm{Q}(\mathrm{x}, \mathrm{y}, \mathrm{t})$ which is taken into consideration as a boundary condition.

\section{EXPERIMENTAL SETUP}

Two pieces of $8 \mathrm{~mm}$-thick Aluminum 6061-T651 slabs, each having the dimensions of $75 \times 250 \mathrm{~mm}$ are welded using Friction Stir Welding method (Fig. 1).

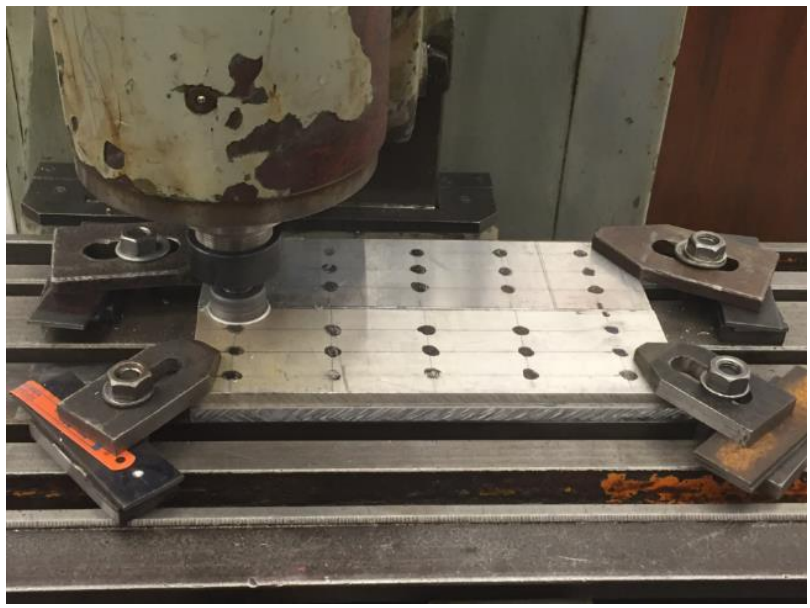

Figure 1. Experimental setup

Analysis is based on $5 \times 7=35$ temperature measurements at each time step which amounts to a total of 175 readings, as shown in Fig.2.

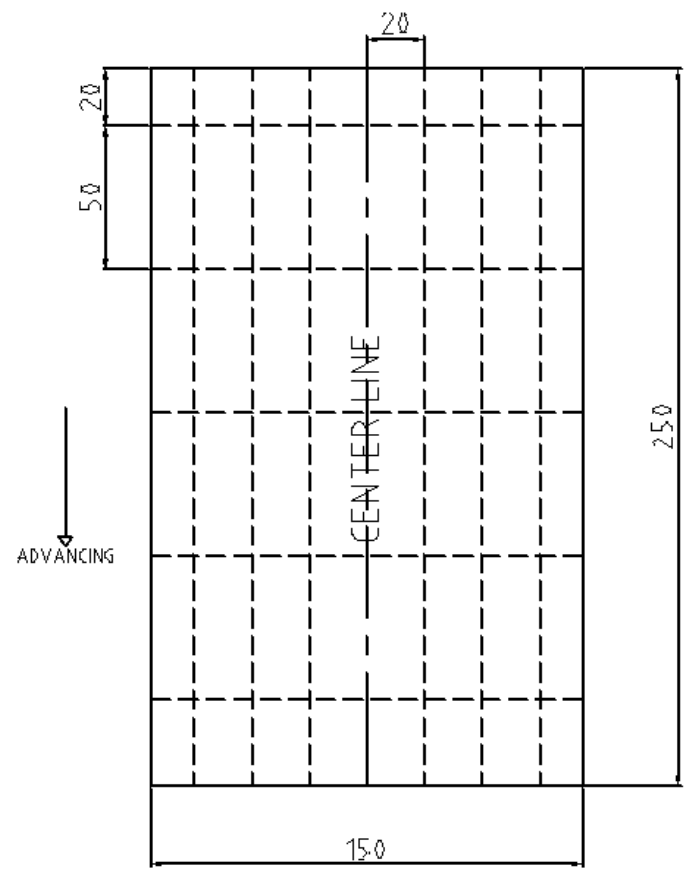

Figure 2. Experimental domain

The two pieces comprise of a $250 \times 150 \times 8 \mathrm{~mm}$ slab when welded. The stirring tool used for welding is a $30 \mathrm{~mm}$-diameter and $15 \mathrm{~mm}$-high cylinder made of H13 tool steel. The total height of the stirring tool is $65 \mathrm{~mm}$. The tool is attached to the spindle of a milling machine model FU 251. A rotational speed of $800 \mathrm{rpm}$ and an advancement speed of $12.5 \mathrm{~mm} / \mathrm{min}$ have been used throughout the experiment. Temperature measurements have been performed using an infrared thermometer (GEO Fennel Model Firt 550). The temperature measuring nodes have been painted using a matt black permanent marker to minimize the effect of reflection, thus making the surface emissivity close to unity $(\varepsilon=1)$ at temperature measurement points. Temperatures are measured every $50 \mathrm{~mm}$ in advancing direction $(y)$ and every $20 \mathrm{~mm}$ in lateral direction $(x)$. Measurements have thus been taken every 4 minutes which correspond to a stirring tool advancement speed of $12.5 \mathrm{~mm} / \mathrm{min}$.

The machine's electrical power input has been calculated using

$\mathrm{P}=\sqrt{3} \operatorname{EICos} \Phi$

where the current (I) and voltage measurements (E) are obtained using a clamp multi-meter, Fluke Model 374. The net heat input into the experimental domain is then calculated using the expression $\mathrm{P}_{\text {net }}=\mathrm{P}_{\text {load }}-\mathrm{P}_{\text {idle. }}$. This is the actual heat input into the welded pieces where $\mathrm{P}_{\text {load }}$ and $\mathrm{P}_{\text {idle }}$ are the electrical power inputs when load is applied and when the machine is idle, respectively. The net heat input into the experimental domain is then calculated to be $1650 \mathrm{~W}$, using Eq. 3. However, about $10 \%$ of this power can be considered as the heat loss by axial conduction through the welding tool into the spindle of the milling machine [7], thus making the net heat input into the domain $1500 \mathrm{~W}$.

\section{NUMERICAL MODEL}

In the numerical modeling, a heat transfer problem is considered where a circular heat source with a radius $\mathrm{R}$ is traveling in the $x$ direction with a velocity of $12.5 \mathrm{~mm} / \mathrm{min}$. Its intensity has a distribution with a peak value of $\mathrm{q}_{\mathrm{o}}$ which is the heat flux applied at a circular spot to represent the $3 \mathrm{~mm}$ diameter rotating tool. For a traveling heat source, it is not possible to have domain boundaries, or even a mesh, that fits the heat flux at all times. The heat flux itself can be entered in a straightforward manner, using a mathematical description. The variable for the radial coordinate, $\mathrm{r}$ can be expressed as $r=\sqrt{(x-v t)^{2}+y^{2}}$. Thus the heat flux can be written as $q(x, y, t)=q_{o}\left[1-\left(\frac{r}{R}\right)^{2}\right]$, for values of $\mathrm{r}<\mathrm{R}[11]$.

Dimensions of the domain: $\mathrm{LxWxH}=250 \times 150 \times 8$ in millimeters, as shown in Fig.3.

Parameters of the numerical models are as follows:

Heat input, $\mathrm{Q}=1500 \mathrm{~W}$

Diameter of heat application site $=3 \mathrm{~mm}$

Ambient temperature, $\mathrm{T}_{\mathrm{amb}}=293^{\circ} \mathrm{K}$

Convective heat transfer coefficient, $h_{\text {top }}=6 \mathrm{~W} \cdot \mathrm{m}^{-2} \cdot \mathrm{K}^{-1}$ for upper and lateral surfaces

Convective heat transfer coefficient, $\mathrm{h}_{\mathrm{bot}}=200 \mathrm{~W} \cdot \mathrm{m}^{-2} \cdot \mathrm{K}^{-1}$ for lower surface. This artificially high convective heat transfer coefficient corresponds to the inverse of the contact heat resistance between the welded plates and the backing plate.

Emissivity value, $\varepsilon=0.2$ due to the shiny surface of aluminum slabs, to account for the heat loss via radiation. 
Thermo-physical properties of AA-6061-T651 are calculated against varying temperatures using fitting curves obtained from the tabular data [12].

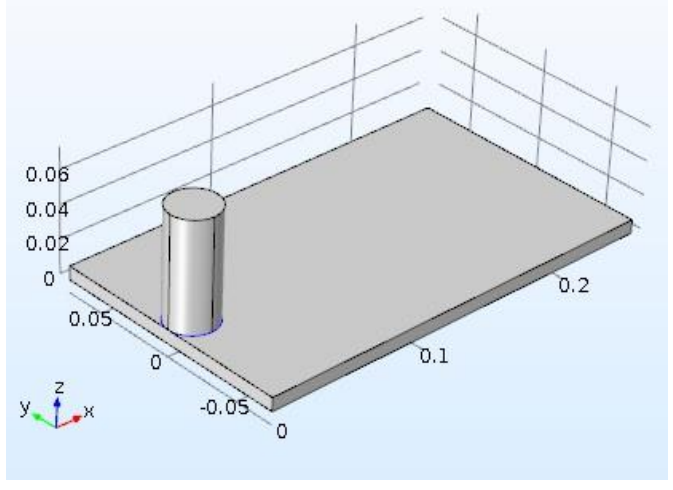

Figure 3. Numerical domain

The numerical domain is meshed (excluding the tool) using 4116 tetrahedral and 2734 triangular elements as shown in Fig. 4. "Heat transfer in solids" as physics and "Time Dependent" as study are selected.

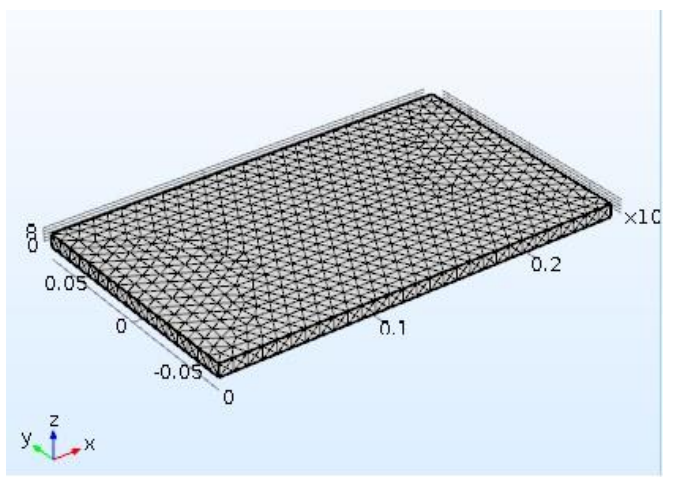

Figure 4. Meshed 3-D domain

\section{RESULTS}

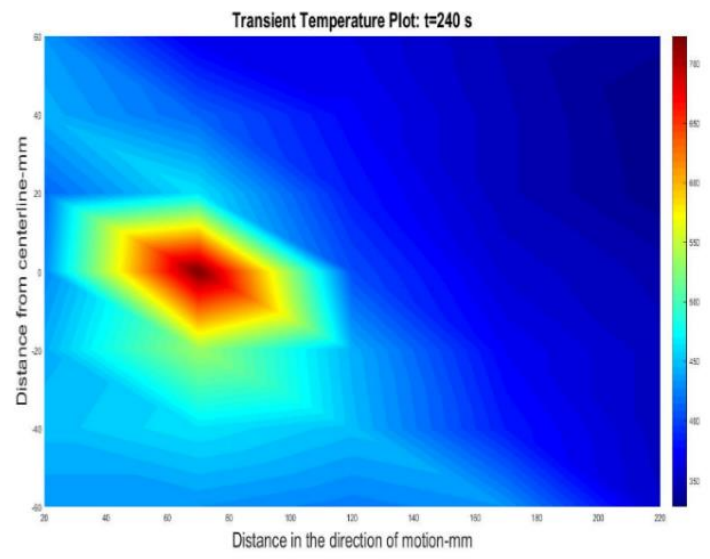

Figure 5. Centerline temperature distribution at $240 \mathrm{~s}$

Fig. 5 through 8 represent the temperature distributions obtained from the experiments as the stirring tool advances, using a Matlab $^{\odot}$ color mapping scheme and graphics. Distortions are due to the mapping algorithm and lack of precision of temperature measurements which are not obtained from a simultaneous measurement method using thermocouples as in the case of automated data acquisition system, instead from a simple manual measurement method that is expected to have deviations, both as values and timewise.

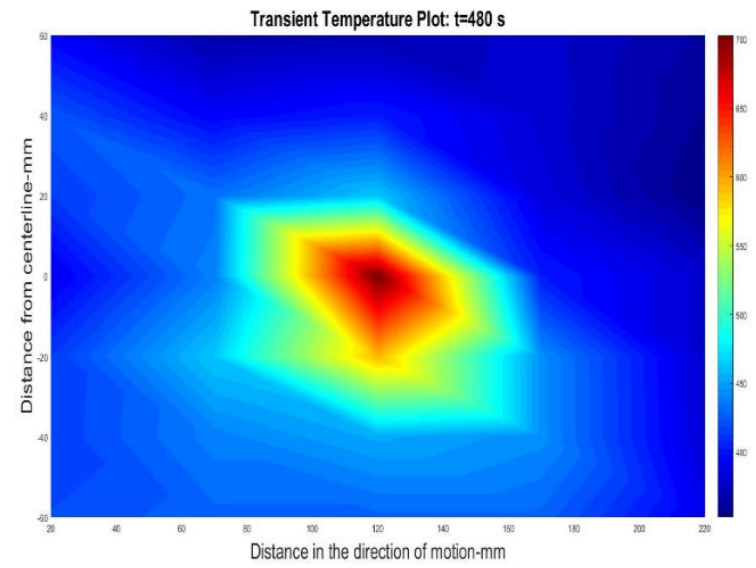

Figure 6. Centerline temperature distribution at $480 \mathrm{~s}$

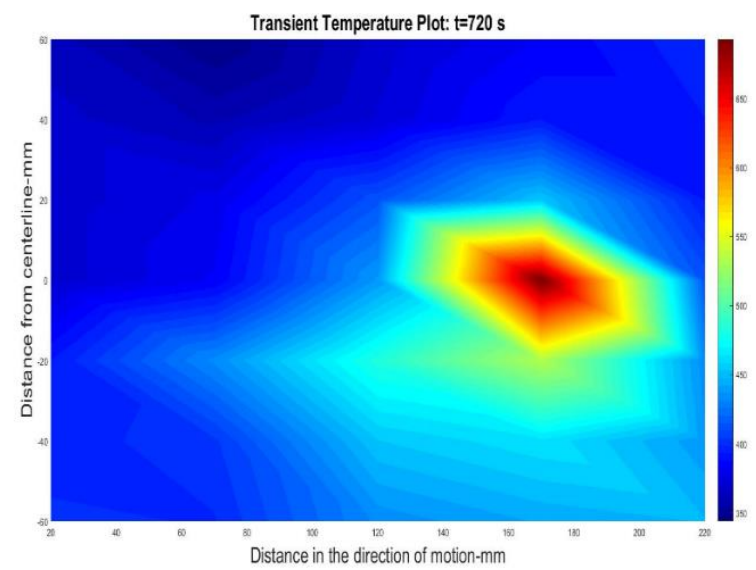

Figure 7. Centerline temperature distribution at $720 \mathrm{~s}$

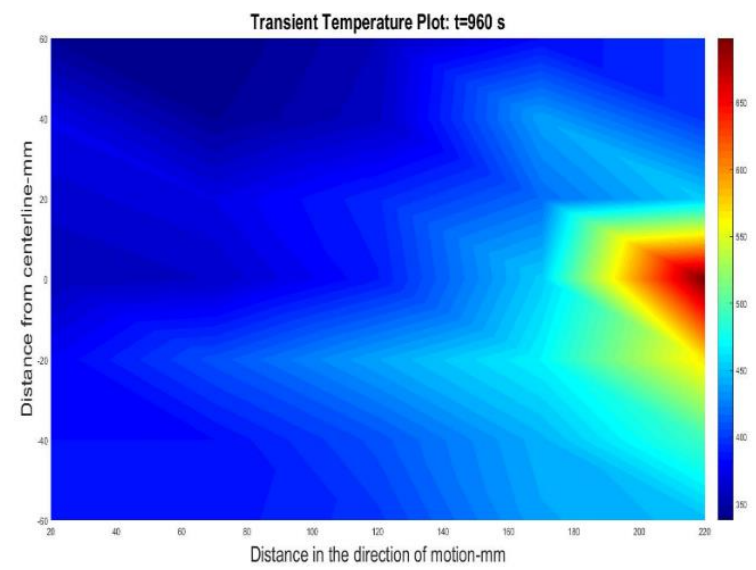

Figure 8. Centerline temperature distribution at $960 \mathrm{~s}$ 


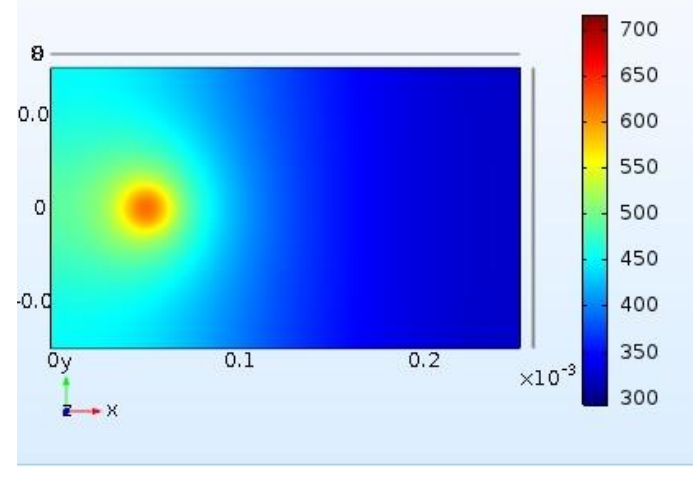

Figure 9. Centerline temperature distribution at $240 \mathrm{~s}$

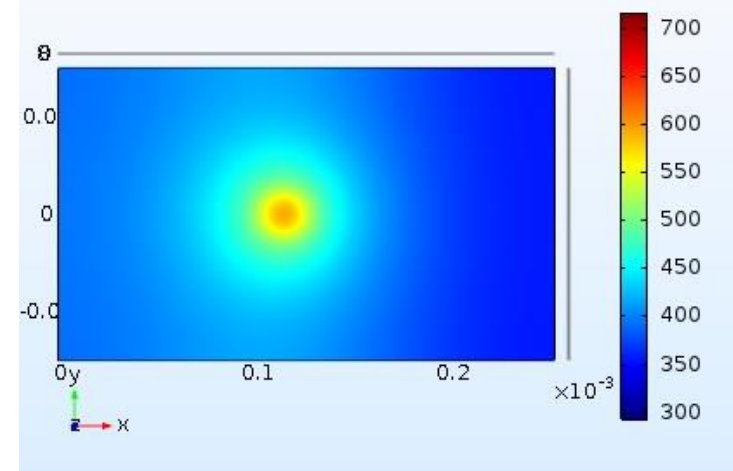

Figure 10. Centerline temperature distribution at $480 \mathrm{~s}$

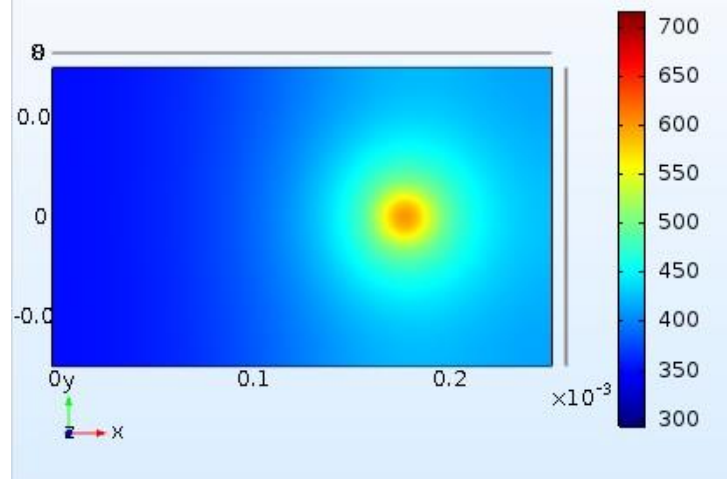

Figure 11. Centerline temperature distribution at $720 \mathrm{~s}$

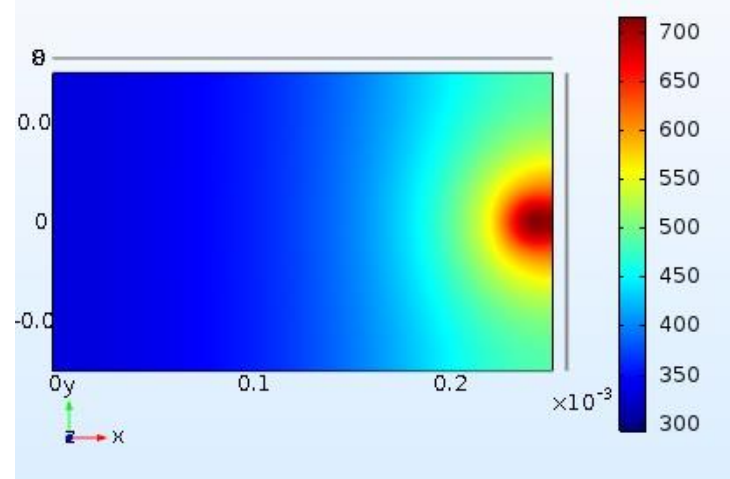

Figure 12. Centerline temperature distribution at $960 \mathrm{~s}$

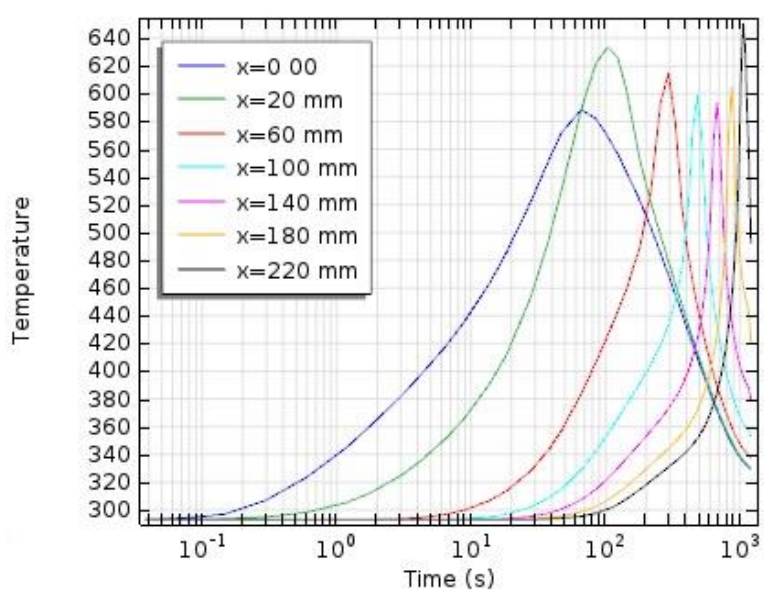

Figure 13. Centerline temperature; location vs. time

Fig. 9 through 12 show the $\mathrm{Comsol}^{\odot}$ simulation results as temperature distribution at various time steps. Fig. 13 shows the centerline temperature of the numerical domain vs. time for various distances in the direction of advancement.

An additional calculation is performed to verify the heat input into the piece to be welded. Taler and Duda [13] provides the following analytical solution for moving heat sources of power on a metal plate:

$$
\theta=\left(\xi, r_{t}\right)=\frac{\dot{Q}_{o}}{2 \pi \lambda r_{t}} \exp \left[-\frac{v}{2 a}\left(\xi, \boldsymbol{r}_{t}\right)\right]
$$

where $\theta$ is the transient excess temperature (T-Tinf), $\dot{Q}_{o}$ is the heat input in Watts, $v$ is the advancement velocity of the tool, $\xi=x-v t$ and $r_{t}=\sqrt{\xi^{2}+y^{2}}$.

Above Eq. (4) has been calculated against $\mathrm{x}$ and $\mathrm{t}$, taking $\mathrm{y}=0$, i.e. centerline and plotted as shown in Fig. $14 . \dot{Q}_{o}$ is calibrated such that both $\mathrm{Comsol}^{\odot}$ and analytical results are substantially close to each other. It is then seen that this condition is met when $\dot{\boldsymbol{Q}}_{\boldsymbol{o}}=\mathbf{1 5 0 0} \boldsymbol{W}$ as stated before, verifying the previous heat input calculation.

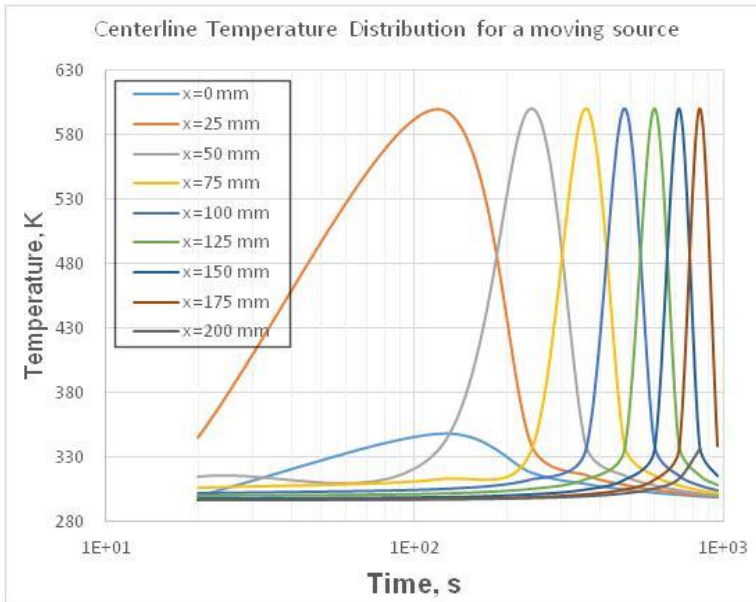

Figure 14. Centerline temperature; location vs. time

\section{CONCLUSIONS}

In this study, three dimensional transient heat transfer analysis of Friction Stir Welding of two 8mm-thick AA-6061- 
T651 (an aluminum alloy) slabs is performed numerically using the commercial software $\mathrm{Comsol}^{\odot}$. The results are then compared to those obtained in a series of experiments conducted by the authors of this paper, validating the numerical model with success. It has thus been shown that $\mathrm{Comsol}^{\odot}$ is a powerful computational instrument in dealing with transient heat transfer problems in solids where a moving boundary heat flux is applied. It can be concluded that with careful modeling, the software is very capable to produce reliable solutions in similar problems, as shown in this work, thus making it unnecessary to prepare expensive experimental setups and spending extensive time to conduct experiments.

\section{REFERENCES}

[1] Thomas MW, Nicholas J, Needham JC, Murch MG, Templesmith P, Dawes CJ. (1995). Friction stir butt welding, GB Patent Application no. 9125978-8, 1991; US Patent no. 5460317, 1995.

[2] Roy BS, Saha SC, Barma JD. (2012). 3-D modeling \& numerical simulation of friction stir welding process. Adv. Mater. Rsrch., 488-489, 1189-1193. https://doi.org/ 10.4028/www.scientific.net/AMR.488489.1189

[3] Chao YJ, Qi X, Tang W. (2003). Heat transfer in friction stir welding-experimental and numerical studies. Int. J. Manuf. Sci. Eng. 125(1): 138-145. https://doi.org/ $10.1115 / 1.1537741$

[4] Song M, Kovacevic R. (2003). Numerical and experimental study of the heat transfer process in friction stir welding. Proc. Inst. Mech. Eng. B 217B: 73-85. https://doi.org/ 10.1243/095440503762502297

[5] Song M, Kovacevic R. (2004). Heat transfer modelling for both workpiece and tool in the FSW process a coupled model. Proc. Inst. Mech. Eng. B, 218B: 17-33. https://doi.org/ 10.1115/1.1537741

[6] Song M, Kovacevic R. (2003). Thermal modeling of friction stir welding in a moving coordinate. Int. J. Mach. Tools Manuf. 43: 605-615. https://doi.org/ 10.1016/S0890-6955(03)00022-1

[7] Schmidt HB, Hattel JH. (2008). Thermal modelling of friction stir welding. Scripta Mater 58: 332-337. https://doi.org/ 10.1016/j.scriptamat.2007.10.008

[8] Schmidt HB, Hattel JH. (2004). Heat source models in simulation of heat flow in friction stir welding. Int. J. of Offsh. Pol. Eng. 14(4): 296-304.

[9] Mourad D, Hedj O, Rachid L, Ahmed M. (2017). Experimental characterization of the Heat Affected Zone (HAZ) properties of $100 \mathrm{Cr} 6$ steel joined by rotary friction welding. Math. Mod. Of. Eng. Problems 4(1): 43-47. https://doi.org/ 10.18280/mmep.040109
[10] Vedat SA. (1966). Conduction Heat Transfer. Addison Wesley, 32-36. ISBN 10: 0201003597 / ISBN 13: 9780201003598

[11] Henrik S. (2016). How to make boundary conditions conditional in your simulation [Web log post]. https://www.comsol.com/blogs/how-to-make-boundaryconditions-conditional-in-your-simulation/, accessed on July 4, 2017.

[12] Taylor RE, Groot H, Goertz T, Ferrier J, Taylor DL. (1998). Measurement of the electrical resistivity of metals up to and above melting temperature. High TempHigh Pressures, 30269-275. https://doi.org/ 10.1002/adem.200390007

[13] Taler J, Duda P. (2006). Solving Direct and Inverse Heat Conduction Problems. $\quad$ Springer, 785. https://doi.org/ 10.1007/978-3-540-33471-2

\section{NOMENCLATURE}

$\begin{array}{ll}\mathrm{C}_{\mathrm{p}} & \text { specific heat, } \mathrm{J}_{\mathrm{kg}} \mathrm{kg}^{-1} \cdot \mathrm{K}^{-1} \\ \mathrm{E} & \text { voltage, volts } \\ \mathrm{h} & \text { heat transfer coefficient, W. } \mathrm{m}^{-2} \cdot \mathrm{K}^{-1} \\ \mathrm{H} & \text { thickness of the slabs, } \mathrm{mm} \\ \mathrm{I} & \text { current, amperes } \\ \mathrm{k} & \text { conductivity, W. } \mathrm{m}^{-1} \cdot \mathrm{K}^{-1} \\ \mathrm{~L} & \text { length of the slabs, } \mathrm{mm} \\ \mathrm{P} & \text { electrical power, watt } \\ \mathrm{Q} & \text { heat, watt } \\ \mathrm{q} & \text { heat flux, W.m } \mathrm{m}^{-2} \\ \mathrm{~T} & \text { temperature, }{ }^{\circ} \mathrm{C} \text { or }{ }^{\circ} \mathrm{K} \\ \mathrm{r} & \text { radial distance, } \mathrm{m} \\ \mathrm{t} & \text { time, } \mathrm{s} \\ \mathrm{X} & \text { longitudinal dimension, mm } \\ \mathrm{y} & \text { lateral (sideways) dimension, } \mathrm{mm} \\ \mathrm{V} & \text { velocity, m. } \mathrm{s}^{-1} \\ \mathrm{~W} & \text { width of the slabs, mm }\end{array}$

\section{Greek symbols}

$\begin{array}{ll}\alpha & \text { thermal diffusivity, } \mathrm{m}^{2} \cdot \mathrm{s}^{-1} \\ \varepsilon & \text { emissivity, }- \\ \Phi & \text { phase angle, } \mathrm{rad} \\ \rho & \text { density, } \mathrm{kg} \cdot \mathrm{m}^{-3} \\ \omega & \text { angular frequency, rad. } \mathrm{s}^{-1}\end{array}$

\section{Subscripts}

$\begin{array}{ll}\text { amb. } & \text { ambient } \\ \text { top } & \text { upper surface of the slab } \\ \text { net } & \text { amount left after the losses } \\ \text { bot. } & \text { bottom surface of the slab }\end{array}$

